\title{
Estructura agraria, familia troncal, mercado de trabajo y redes sociales en el mundo rural, Cataluña siglos XVIII-XIX $^{1}$
}

\author{
Llorenç Ferrer-Alós \\ Universidad de Barcelona, España \\ Ilferrer@ub.edu
}

Cita sugerida: Ferrer-Alós, L. (2018). Estructura agraria, familia troncal, mercado de trabajo y redes sociales en el mundo rural, Cataluña siglos XVIII-XIX. Mundo Agrario, 19(40), e079. https://doi.org/10.24215/15155994e079

Recibido: 3 de abril de 2017 - Aceptado: 11 de diciembre de 2017 - Publicado: 26 de marzo de 2018 http://creativecommons.org/licenses/by-nc-sa/4.0/deed.es_AR 


\title{
Estructura agraria, familia troncal, mercado de trabajo y redes sociales en el mundo rural, Cataluña siglos XVIII-XIX ${ }^{1}$
}

\author{
Agrarian structure, stem family, labour market and social networks in rural Catalonia (18th-19th Century) \\ Llorenç Ferrer-Alós \\ Universidad de Barcelona, España \\ llferrer@ub.edu
}

\section{RESUMEN:}

A partir de la descripción de la estructura de la propiedad y del sistema familiar en Cataluña en los siglos XVIII y XIX se define el lugar que ocupaba cada individuo. A partir de esta definición se analizan las distintas redes sociales que se generaron, desde el entramado social derivado de los encadenamientos matrimoniales, del papel que jugaban las mujeres en la relación entre las casas, los parentescos ficticios, la relación familia e Iglesia a través de los hijos que entraban en la Iglesia, las redes derivadas de la emigración a la ciudad de algunos hijos, las prácticas desarrolladas para poder acceder a las masoverías o cómo las familias modestas se insertaban en el mercado de trabajo para obtener los recursos que no les proporcionaba la explotación campesina. Las redes, pues, tienen sentido cuando se estudian relacionadas con la forma en que los individuos acceden a los recursos.

Palabras ClaVe: Redes sociales, Estructura de la propiedad, Sistema familiar, Encadenamientos matrimoniales, Parentescos ficticios, Emigración, Cataluña, Siglo XVIII, Siglo XIX.

\section{Abstract:}

From the description of the ownership structure and family system in Catalonia in the eighteenth and nineteenth centuries the site of each individual is defined. From this definition we analyze the different social networks that were generated, the social fabric derived from the matrimonial chains, the role of women in the relationship between houses, fictional kinship, family and Church relationship through children coming into the Church, the networks derived from the emigration to the city of some children, the practices developed to gain access to the masoverías, the way in which modest families inserted in the labor market to obtain the resources that did not provide them the peasant exploitation. Networks make sense when they are studied related to the way individuals access resources.

KEYWORDS: Social networks, Property structure, Family system, Matrimonial chains, Fictional kinship, Emigration, Catalonia, 18th Century, 19th Century.

Los individuos y las familias no viven aislados, necesitan satisfacer sus necesidades materiales e inmateriales a través de la relación con otros individuos con los que intercambiarán información para poder acceder a recursos diversos, materiales e inmateriales. Estas relaciones establecidas de forma simétrica o asimétrica son las redes sociales que no se pueden entender sin conocer la estructura social (la forma en que se producen y reparten los recursos materiales, quién controla el excedente producido, quién tiene la fuerza en la comunidad para imponer determinado reparto, etc.) ni los mecanismos de reproducción social que la historia ha ido remodelando a lo largo del tiempo.

Las redes sociales no se pueden estudiar de forma abstracta, deben concretarse en un espacio, en un tiempo y, seguramente, en grupos sociales determinados. Lo que nos proponemos es estudiar el funcionamiento de las redes sociales en Cataluña, en los siglos XVIII y XIX, y en un mundo rural en el que convivían grupos sociales diferentes pero relacionados entre si por la actividad económica que desarrollaban. Para ser más precisos, nos centraremos en la Catalunya Vella, donde predominaba el sistema de masía y concretamente en las zonas vitícolas en las que predominaba el contrato de rabassa morta. 


\section{LA ESTRUCTURA DE LA PROPIEDAD Y EL SISTEMA FAMILIAR}

En un área significativa de la Catalunya interior, la salida de la crisis provocada por la peste negra fue un proceso de despoblación general y, al mismo tiempo, un proceso de concentración de la tierra en unas unidades que se situaban en las 100 ha de media y que tenían en su interior una vivienda que era conocida como masía, que era lugar de residencia de la familia pero también el centro de producción y transformación agraria (Congost, Jover, Biagioli, 2003; Ferrer Alòs, 1987). Una masía, pues, tenía tierras dedicadas a cultivo, bosques y pastos. Toda la tierra estaba acaparada y no habia comunales.

Los campesinos de masía no eran en realidad propietarios absolutos de la tierra, disponían del dominio útil a través de un contrato enfitéutico. Las guerras remensas que estos campesinos mantuvieron contra sus señores hicieron que la renta que pagaban fuera ridícula e insignificante y, al mismo tiempo, que se pudieran pasar todos los derechos sobre la tierra de padres a hijos. Con esta extensión de tierra, las masías serían la base de la organización agraria y, al mismo tiempo, la base para la aparición de un campesinado acomodado (Ferrer Alòs, 2014; Ferrer Alòs, 2015).

Tener tierra no era suficiente para poder acumular renta y riqueza. Algunos de estos campesinos no fueron capaces de reproducir esta explotación, por lo que algunos entraron en un proceso de endeudamiento que los llevó a vender sus derechos sobre la tierra, por lo que otros campesinos se enriquecieron en este proceso. Al mismo tiempo, el sistema hereditario que veremos después facilitaba una cierta concentración de masías en pocas manos. Con el paso de tiempo, algunos campesinos de masía se enriquecieron en este proceso de concentración de tierras.

\section{Figura 1. Esquema del acceso a la tierra en la Catalunya Vella}

Figura 1

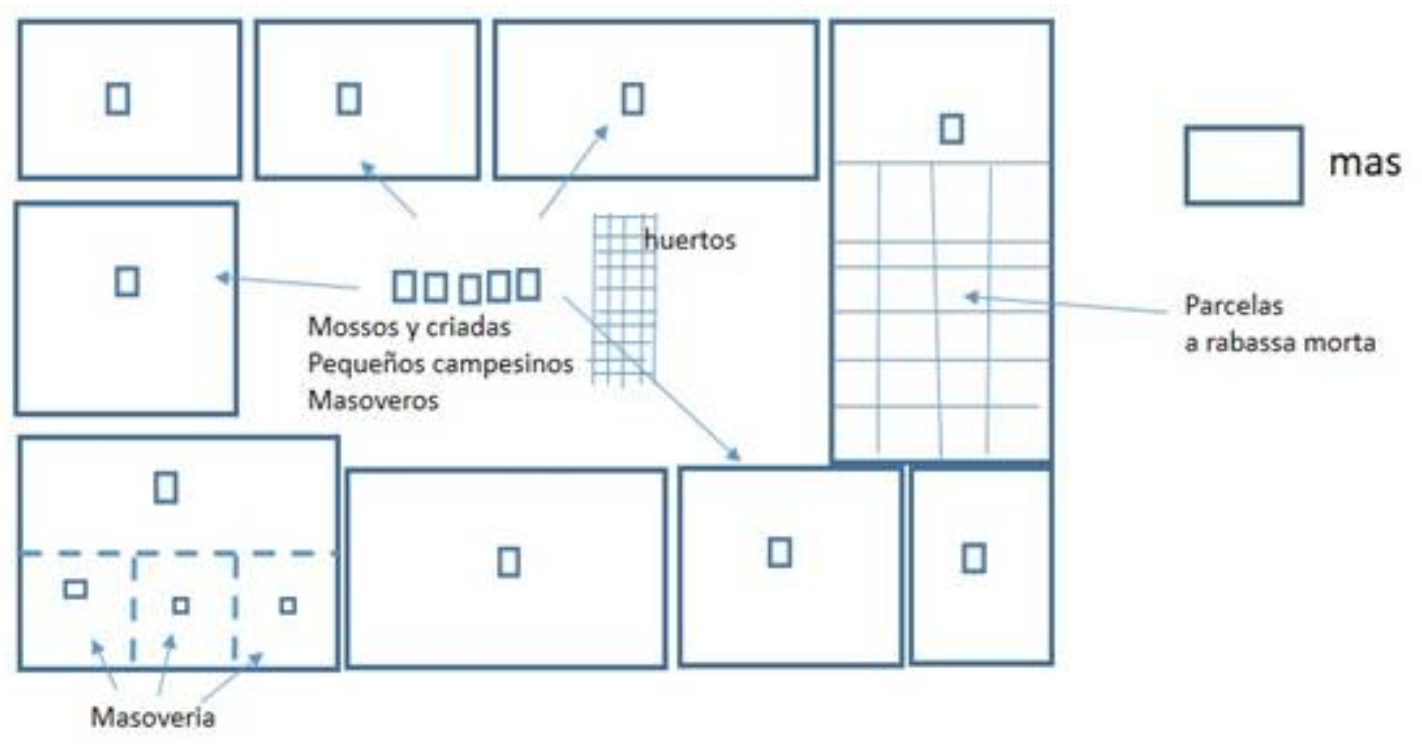

Esquema del acceso a la tierra en la Catalunya Vella Fuente: Elaboración propia.

La explotación de estas masías generó básicamente tres tipos de situaciones: a) Para explotar una parte de las tierras, las masías necesitaban mano de obra externa permanente (mossos que vivían en la misma masía) 
y de forma temporal (colles - grupos organizados de personas- que iban de casa en casa cuando los cultivos requerían una gran cantidad de trabajo).

b) Para poner en cultivo nuevas tierras a partir de bosques y yermos se podía fragmentar la explotación principal en pequeñas explotaciones dentro de las cuales se construía una pequeña casa. Estas explotacions recibían el nombre de masoverias y se cultivaban mediante un contrato de este nombre que implicaba que la familia campesina residiera en la casa. Ello generaba un tipo de campesino conocido como masover (masovero) (Congost Colome, Gifre Ribas, Saguer Hom, Torres, 1999).

c) Para poner en cultivo parte de las tierras se podían ceder pequeños lotes $(2 / 3 \mathrm{ha})$ a pequeños campesinos que residían en los pueblos de los alrededores. Si era para plantar vid, el contrato que organizaba la relación entre estos pequeños campesinos y los campesinos de masía era el de rabassa morta (Colome Ferrer, 2003).

Los pequeños campesinos residían en los pueblos. Tenían casa, algún huerto que cultivaban de forma intensiva en pequeñas zonas de regadío, algunos trozos de tierra propia y, sobre todo, parcelas que les proporcionaban las masías de los alrededores. Algunas familias podían complementar los ingresos con actividades protoindustriales y otras especializarse en los oficios necesarios para producir los bienes y servicios que necesitaba la comunidad (Torras Elias, 1984; Torres, 1995).

Así pues, el mundo rural de la Cataluña Central se articulaba alrededor de los campesinos de masía (unos más acomodados que otros), masoveros y pequeños campesinos. Estos últimos no vivían únicamente del campo, sino de otras producciones locales y protoindustriales. Las redes sociales tenían que construirse a partir de la situación de cada uno en la estructura de la propiedad.

\section{FAMILIA TRONCAL Y SISTEMA DE HEREDERO ÚNICO COMO FORMA DE ORGANIZACIÓN FAMILAR}

¿Cómo se conseguía que a lo largo del tiempo este sistema se fuera reproduciendo? ¿Qué ocurría con los excedentes demográficos? Desde la Edad Media, en Cataluña se fue desarrollando un sistema de heredero único que explica la pervivencia de este modelo, el cual hay que analizar para entender las contradicciones que generaba y cómo se resolvían (Barrera, 1990; Ferrer Alòs, 2007).

En primer lugar, era heredero de la casa y del patrimonio familiar el hijo varón primogénito con dos obligaciones: tener cuidado de los padres y generar recursos para colocar a los hermanos lo mejor posible o, como decían los documentos, "según las posibilidades de la casa". El heredero se quedaba y se casaba en casa; tenía que cuidarla y procurar que generara recursos ya que era el punto de referencia que aseguraba un determinado nivel social a los otros hijos (Ferrer Alòs, 2011).

En segundo lugar, eran las mujeres las que se mudaban de la casa de la que venían a la casa donde iban cuando se casaban. Aportaban una dote al matrimonio que, en principio -aunque era una decisión política de la casa de donde venían-, era la que su familia podía pagar sin poner en peligro su reproducción. Es decir, la dote se correspondía con nivel social de la casa de salida. En este contexto las mujeres estaban orientadas al matrimonio y eran las que religaban las casas y propiciaban algunos intercambios como veremos.

Solo cuando no había hijo varón la heredera era la primera hija -la pubilla-, lo que propiciaba que un hijo varón de otra casa entrara como pubill si se casaba con una pubilla. Esto se daba relativamente en pocos casos, y era lo único que podía propiciar un matrimonio entre un heredero y una pubilla, hecho que producía una unificación de dos patrimonios, la concentración de las tierras, y que una de las dos casas se convirtiera en una masoveria (Ferrer Alòs, 2005b).

Los hijos varones no herederos no tenían casa donde entrar a no ser que hubiera pubillas, situación poco frecuente, por lo que tenían tres salidas: o quedar solteros en la casa -concos, unclus-, o entrar en la Iglesia si la familia podía pagar el acceso, o dejar la casa y emigrar a la ciudad donde aprender un oficio o a un pueblo donde obtener tierras y constituir una explotación agrícola. Así pues, las mujeres eran los nodos de la red que unía a las casas y a los varones con otros mundos como el urbano o el local, o con oficios y actividades alejadas del mundo rural. 
En tercer lugar, los recursos que la casa generaba a cada generación no eran suficientes para colocar a los hijos e hijas en el mismo nivel social que el del heredero, por lo que se producía un inevitable descenso social. Este es un elemento fundamental para entender el sistema. Como hemos explicado en otros lugares, las hijas recibían una dote inferior a la que aportaba la mujer que se casaba con el heredero, lo que indica que el heredero se casaba socialmente hacia arriba y las hijas lo hacían hacia abajo. Asimismo, los hijos varones segundones eran los más perjudicados ya que la legítima que recibían tenía que servir para conseguir un patrimonio y poder casarse con una mujer cuya dote fuera equivalente. Este nuevo patrimonio estaba muy lejos de la casa que recibía su hermano heredero. Las familias desarrollaron estrategias muy diversas para intentar reducir este descenso social (causas pías para casar doncellas que incrementaban el valor de las dotes, intercambio de hijos entre casas, celibato definitivo, acceso a la Iglesia de forma sistemática, permitir a los segundones pequeños negocios complementarios para mejorar su legítima, etc.) (Ferrer Alòs, 1993).

En las casas más modestas - pequeñas masías, masoveros, pequeños campesinos-, evitar el descenso social era más difícil, ya que los patrimonios que generaban los recursos eran muy escasos. Es por ello que, a diferencia de las casas de campesinos acomodados, tenían que procurar recursos complementarios fuera de las casas para intentar reproducirse socialmente. Es decir, demandaban trabajo desde muy jóvenes y lo encontraban en el servicio doméstico (mossos, criadas, colles.., etc.) que se necesitaba en las masías más acomodadas.

El análisis de la estructura de la propiedad, del acceso a los recursos derivados de la explotación de la tierra y del sistema familiar utilizado permite comprender mucho mejor cuáles son los nodos de estas redes sociales que habilitaban a los individuos a desarrollar sus capacidades y su reproducción social.

\section{El Sistema dotal Y DE heredero ÚNICO, BASE DE LA RED DE RELACiONES ENTRE INDIVIDUOS DE DISTINTO NIVEL SOCIAL}

Si el heredero se casaba con una mujer que venía de una casa más acomodada y las hijas entraban en una casa socialmente inferior (el importe de la dote nos lo indica), los actos familiares de la vida cotidiana (bodas, bautizos, entierros, fiesta de la casa) relacionaban en un mismo espacio a una familia más acomodada con otras (donde se habían casado las hijas) menos acomodadas. Si aceptamos el supuesto de que las hijas se iban encadenando hacia abajo ya que siempre se casaban con casas de valor inferior, en un evento familiar, la familia reunía a parientes que estaban conectados con dos rangos sociales hacia arriba y dos rangos sociales hacia abajo. Esta situación era muy importante ya que en una misma mesa se tenía información y se podían intercambiar recursos (un pastor, un mosso para trabajar, los precios de los productos, situación de otras casas, beneficios eclesiáticos vacantes, etc.) (Ferrer Alòs, 2004)

¿Esto era así?, ¿o es simplemente un supuesto? La dote indica el nivel social pero detrás está una familia que toma decisiones, que puede decidir sacrificar unas hijas para mejorar a otra, que puede decidir pagar por encima de sus posibilidades, etc. No podemos reducir la dote a un indicador matemático. Sin embargo, si la dote no respondía a las posibilidades de la casa, al final podía conducir a la ruina. Ello nos hace pensar que, con un cierto margen, las dotes se correspondían con un nivel social específico (Ros Massana, 2010).

A partir de aquí, hemos realizado un ejercicio que no es fácil metodológicamente. Hemos partido del matrimonio de un heredero. Sabemos la dote que le aporta su mujer. A continuación, hemos buscado el matrimonio de la hermana de este heredero con el heredero de otra casa. Sabemos también la dote que aporta esta mujer. Después, sabemos la dote que recibió la hermana de este segundo heredero cuando entró en otra casa y así sucesivamente. Todas estas parejas viveron en los mismos años (los matrimonios se produjeron entre 1754 y 1768).

En cinco encadenamientos matrimoniales, en cuyo centro se encuentra Valentí Illa, campesino de masía de Avinyó que recibió 700 libras de su mujer, quien provenía del mas Santmartí de Serraïma, casó a sus hijas con una dote de 225 libras. En este caso, la casa en la que entró la hija ya no era una masía sino la de un campesino 
modesto que vivía en el pueblo de Balsareny. Y si seguimos descendiendo, las hijas de Anton Bassany lo hicieron con una dote de 65 libras, con un campesino aún más modesto. Hacia arriba podemos observar el mismo proceso hasta llegar al mas Frabregas de Sant Feliu Sasserra que casó una hija com el heredero del mas Farreras, con una dote de 1600 libras.

\section{Figura 2}

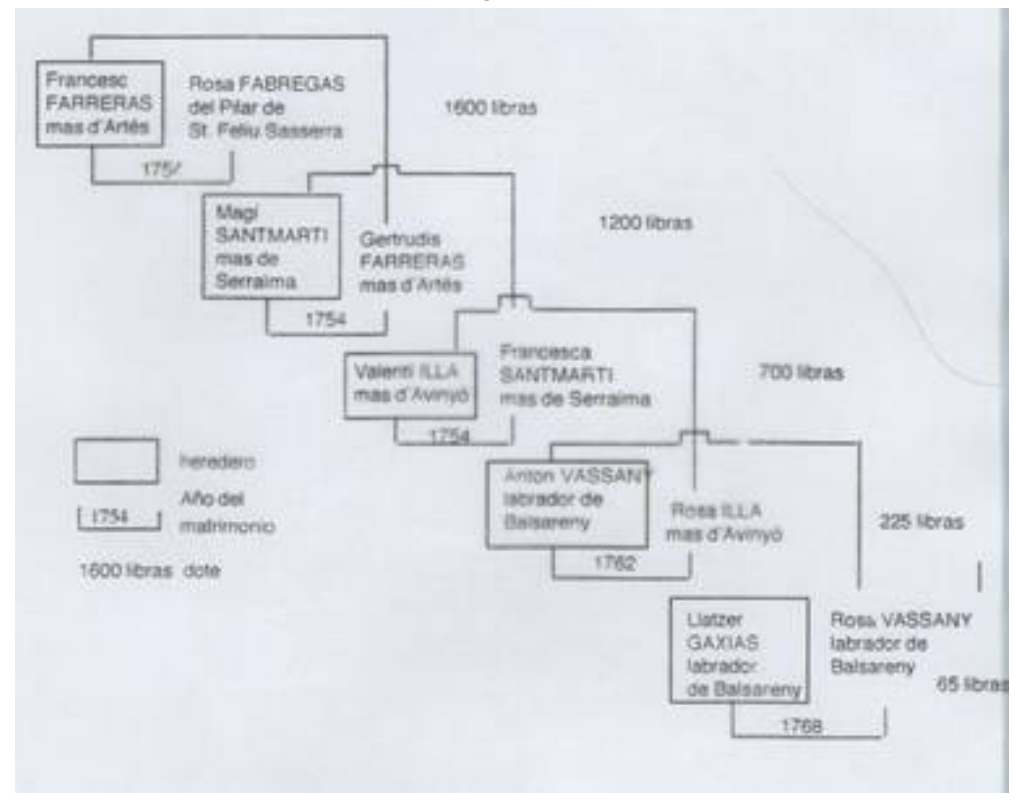

Encadenamientos matrimoniales ascedentes y descendentes en Cataluña (siglo XVIII) Fuente: Elaboración propia a partir de los capítulos matrimoniales de estos años (Arxiu Comarcal del Bages, ACB).

Así pues, el mundo rural de la Cataluña Central se articulaba alrededor de los campesinos de masía (unos más acomodados que otros), masoveros y pequeños campesinos. Estos últimos no vivían únicamente del campo, sino de otras producciones locales y protoindustriales. Las redes sociales tenían que construirse a partir de la situación de cada uno en la estructura de la propiedad.

Evidentemente es un caso concreto y tendrían que reconstruirse muchos más, pero con sus variantes y quizás pequeñas rupturas, el esquema funciona del modo descrito. Cada casa es un nodo de una red en la que las mujeres son las que realizan el enlace. Imaginemos una fiesta familiar en casa de Valentí Illa; en la mesa se sentaría un heredero de una casa de mucho más valor (mas Santmartí) que, al mismo tiempo, tendría todos los contactos con otra aún más potente (el mas Farreras), con otros herederos (las casas en que habrían entrado las hijas) más modestos que, al mismo tiempo, estaban enlazados con campesinos que ya no tenían masía y que residían en el pueblo tal como hemos descrito más arriba.

Esta imagen es la que nos lleva a proponer que la contradicción del sistema dotal, en el sentido de no generar los recursos suficientes, establecía a través del matrimonio una red en la que convivían niveles sociales distintos, y esto era fundamental para traspasar información de todo tipo (económica, política, legal, etc.), para explorar mercados de trabajo (buscar criados y mossos en familias más modestas que necesitaban este trabajo), para conocer situaciones patrimoniales desde puntos de vista diversos que podían conducir a enlaces matrimoniales, y para mitigar o reducir posibles conflictos sociales. 


\section{El PAPEL DE LAS MUJERES EN LA CREACIÓN DE LAS REDES DE PARENTESCO}

Las mujeres eran fundamentales en esta estructura social. Su destino era dejar la casa, casarse con un heredero de otra masía donde iban a vivir y a integrarse para el resto de sus días. Se convertía en la "jove" de la familia, en contraposición a "la vella" que había entrado en la generación anterior. La dote marcaba el nivel social de la casa donde entraba.

Eran pues las mujeres las que concretaban las alianzas con otras casas y, a partir de ahí, se establecían lazos emocionales, económicos y sociales, lo que posibilitaba todo tipo de intercambios o negocios con las casas emparentadas.

\section{EL MERCADO MATRIMONIAL}

A medida que subimos en el nivel social el número de casas se reduce, por lo que el nivel social determinaba la geografía de los matrimonios. Cuanto mayor era el nivel social más lejos tenía que buscarse la esposa. ¿Cómo circulaba la información entre las casas para saber que en una u otra había interés en casar a una hija o a un heredero? ¿Cómo se tomaba la decisión de aceptar o no un matrimonio determinado?

El nivel social determinaba el nivel de intervención de la familia. Aunque el matrimonio era una cuestión de interés, el interés aumentaba en función del nivel social porque había muchos más recursos que proteger. Los pequeños campesinos tenían un mercado más amplio entre los iguales aunque también intervinieran razones de interés en la elección de pareja.

En un mundo de masías dispersas por el territorio, la información circulaba especialmente entre los individuos de algunos oficios que iban de casa en casa a desarrollar alguna actividad y, por tanto, podían conocer la situación de cada una de ellas. Estos trabajadores eran los sastres que pasaban temporadas elaborando la ropa para la casa, los paraires que iban a trabajar la lana y dejarla preparada para hilar y tejer, los arrieros que iban de un lado a otro del país, y todo tipo de comerciantes ambulantes (Violant Simorra, 1992, p. 103); también estaban los cuestores, que iban por las casas llevando una capilla con la virgen o alguna devoción determinada, y los padres mendicantes que iban de casa en casa recogiendo donativos ${ }^{2}$.

Las relaciones económicas y comerciales jugaban también su papel en la concertación de matrimonios. Cuando se quería consolidar una relación económica con otra casa, el matrimonio era una vía a la que se recurría a menudo. En el mas Llobet de Vidreres se realizaron en una generación del siglo XVII diversos matrimonios con casas a las que se habían comprado piaras de cerdos para una sociedad comercial, y el heredero se casó con una hija de unos mercaderes de Blanes con los que se había creado una sociedad mercantil 3 .

Otro papel importante lo jugaban los eclesiásticos. En otros lugares hemos analizado cómo las familias más acomodadas colocaban a los hijos segundones en la glesia para reducir el impacto de su seguro descenso social. Estos curas se iban moviendo por el territorio a medida que iban ascendiendo en le escalafón eclesiástico y tenían una información de primera mano sobre el estado de la casa en sus parroquias. No es de extrañar que fueran tejedores de matrimonios para su familia de origen. Dos ejemplos del mas Roqueta d'Horta d'Avinyó. Bernat Roqueta se casó en el año 1696 con Gerónima Plans, segundona del mas Plans de Sant Joan d'Oló, curiosamente, cuando era párroco de la parroquia Isidre Plans, segundón del mismo mas. En el año 1888, Antonio Rovira, segundón de un mas de Muntanyola -a unos $50 \mathrm{kms}$ de distancia-, era el párroco de la parroquia de Horta y fue clave en el doble matrimonio que se celebró entre Antonia Rovira Estebanell seguramente su cuñada - y Bonaventura Roqueta, y entre la hija de la primera Sebastiana Antonell y el hijo y heredero del segundo, Joan Roqueta (Ferrer Alòs, 1998, pp. 58, 70).

Otro de los mecanismos más seguros en la búsqueda de cónyugue era utilizar las parentelas familiares que se habían abierto a lo largo de diversas generaciones a través de las hijas que habían entrado en otra casa o las 
mujeres que habían entrado de nueras en la propia. En este sentido, las mujeres eran claves. El mas Vila del Soler de Artés nos proporciona algunos ejemplos: hacia el año 1740, Anton Vila del Soler se casó en segundas nupcias con Maria Oller, del mas Oller de Manresa; nada anormal. En el año 1765, el heredero e hijo del primer matrimonio de Anton, Josep, se casó con Caterina Puigrubí de Oristá. Un análisis más fino muestra que una hermana de Caterina se había casado con el heredero del mas Oller. Las dos masías accedieron, a través de la trama familiar, a las hijas de una misma familia (Ferrer Alòs, 1991, p. 40). Este mismo Josep se casó en segundas nupcias con Marianna Vilata. Anton, el siguiente heredero, se casó con Valentina Bertran. Esto no sería nada anormal si no fuera que su segundo apellido era Vilalta. O sea, que otra Vilalta había entrado en el mas Bertran, y ahora una segundona de esta masía entraba de nuera en el mas Vila del Soler; eran primos hermanos (Ferrer Alòs, 1991, p. 40).

Las dispensas del grado de parentesco que otorgaba la Iglesia son un buen indicador de hasta qué punto los matrimonios se celebraban en círculos familiares próximos y la esposa se buscaba en entornos ya conocidos. Santiago de Llobet hace un estudio minucioso del árbol familiar del mas Llobet y aporta ejemplos variados de dobles matrimonios, intercambio de hijos, pero sobre todo de la consaguinidad por la que -hasta cuatro grado- se debía pedir dispensa a la Iglesia. Concluye al final que las descendencias de los siete hermanos Llobet Teixidor, desde 1763 a 1909, estaban todas emparentadas en cinco y seis grados de consanguinidad. Esto ocurría en las familias Llobet, Llavari, Iglesias, Vidal de Llobatera y Albó, visto desde la familia Llobet. Estas familias más acomodadas encontraban sus esposas o sus maridos en unos entornos familiares determinados sobre los que tenían un amplio conocimiento (Llobet Masachs, 2012, pp. 260-265). Algo parecido se produce en masías más modestas de la zona de Horta de Avinyó; allí, las casas Roqueta, Torrentó y Pla fueron intercambiando los hijos entre ellas desde finales del siglo XVIII hasta finales del siglo XIX ${ }^{4}$. Las esposas se encontraban en el propio entorno familiar.

Para familias más modestas, el mercado matrimonial se concretaba en las fiestas populares como aplecs (peregrinajes a determinadas ermitas en días señalados), ferias que se celebraban anualmente, y rosers casamenteros o fiestas del rosario que tenían fama de ser lugares en los que se concertaban las bodas. A ellas acudían las hijas e hijos en edad de casarse para conocer y concertar posibles bodas. Incluso era un lugar para que se vieran las parejas cuyos padres ya habían concertado antes la boda ${ }^{5}$. Era en estos entornos festivos donde el mercado matrimonial era más libre entre los pequeños campesinos, era muy importante desarrollar un código de comunicación para saber la situación de la persona que estaba en aquel entorno. Algunas ferias se conocían como ferias de chicas, a ellas acudían jóvenes de ambos sexos a la búsqueda de una pareja. Entre ellas, se destacaban las de Santa Llucia en Barcelona, en el Vallés o en el Maresme, o la de la Ascensión en Granollers, o el aplec de la miel en Cervià; la feria de Sort (en la que se destacaba un día especial para concertar bodas, que era el día del marchante), la feria de Vilaller, la de la Pobleta de Bellvehí, etc. Estas ferias cubrían toda la geografía catalana (Amades, 1980, p. 246; Violant Simorra, 1992, p. 88). En el Aplec del Trial, en las cercanías de Olot, se practicaba un baile popular con muchos cambios de pareja que ayudaba a los jóvenes a conocerse.

Aunque con poca precisión, Joan Amades (Amades, 1980, p. 251) explica cómo la forma de llevar el vestido era un código (Llaç del davantal tort, busca xicot; davantal al revés no cerca promés; davantal amb caragol, estimat vol $)^{6}$, o el uso de una mantilla blanca indicaba que se buscaba esposo, o el cabello recogido indicaba que se era una mujer casada, o el cabello estirado o con trenzas indicaba que se era mujer casadera. Las bodas a las que se asistía eran otro espacio de socialización que podía llevar a otras bodas ( "bodes porten bodes” "D'un casament en venen cent"). 


\section{PARENTESCOS FICTICIOS COMO RED: PADRINOS Y MADRINAS}

A este entramado que hemos descrito debemos añadir los parentescos ficticios que la Iglesia había desarrollado y que, en la práctica, servían como red de apoyo y de contactos (Munno, 2005). En Cataluña, la elección de padrino o de madrina seguía un orden que tenía que ver con el sistema familiar de heredero único. Conocemos los padrinos y madrinas de los hijos del mas Roqueta de Horta de Avinyó desde el siglo XVII y los hemos ubicado a partir de la genealogía de este mas (Ferrer Alòs, 1998). No tenemos, sin embargo, la genealogía de las nueras que entraron en la casa, por lo que a menudo no conocemos el parentesco de los padrinos que vienen por parte femenina, aunque algunos de ellos pueden deducirse. Entre los padrinos aparecen nombres que no tienen nada que ver con el parentesco de los tíos y tías.

La lógica parece muy clara: el padrino del primer hijo, al margen del sexo, es su abuelo paterno, y la madrina, la abuela materna; en el segundo hijo, son el abuelo materno y la abuela paterna. A continuación empiezan a jugar los hermanos del heredero. A partir del tercer hijo empiezan a jugar los tíos por orden de nacimiento y alternando la línea paterna y la línea materna. Esta lógica solo se puede aplicar si los abuelos viven al nacimiento de los nietos y si los tíos de uno y otro lado son los mismos y con un reparto simétrico de los sexos. Sin embargo, esto no se daba casi nunca debido a la biología, ya que las familias no tenían la misma cantidad de hijos, ni con el mismo equilibrio de sexos, y que cuando los hermanos se iban de casa no todos mantenían las mismas relaciones con la casa de origen. Así pues, aquel esquema teórico sufría muchas variaciones. Podríamos decir que cuando faltaba algún abuelo era substituido por el tío más próximo, y cuando faltaban tíos se podía repetir o recurrir a personas de fuera con los que se mantenía amistad o a personas con un parentesco más lejano.

Figura 3

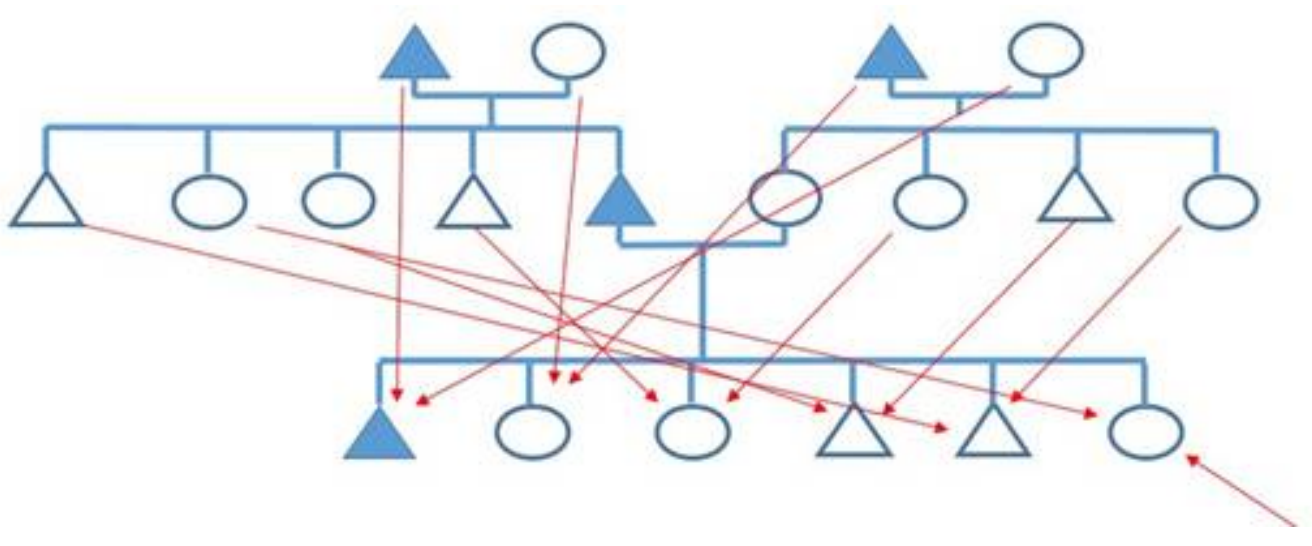

El funcionamiento de los parentescos ficticios en Cataluña (siglo VIII). Padrinos y madrinas Fuente: Elaboración propia.

La etnografía ha señalado algunos papeles simbólicos a los padrinos como pagar parte de la fiesta del bautizo, pagar la palma el día de Ramos, o la mona el día de Pasqua, de hacer regalos en aniversarios y otras fiestas. Sin embargo, este parentesto ficticio pretendía cubrir las emergencias en caso de desaparición de los padres y podía ser una ayuda en momentos determinados del ciclo vital y abría contactos en entornos distintos a la familia de origen. Ello era posible porque abría los contactos al lado paterno y materno a través de segundones varones, algunos de los cuales vivían fuera de la casa en entornos urbanos, y segundonas que habían entrado de nueras en casas de otros espacios geográficos. Ello podía ser especialmente útil para encontrar trabajo, 
esposa, una masoveria disponible, etc. La utilidad en la práctica variaba de un padrino a otro, de una tradición familiar a otra, pero era otro recurso que, en algunos casos, podía jugar un papel importante para el ahijado.

\section{EL PAPEL DE LOS ECLESIÁSTICOS EN LA RED FAMILIAR CUANDO LOS HABÍA}

Entrar en la Iglesia fue un recurso muy utilizado por familias acomodadas de campesinos de masía, abogados, médicos, apotecarios y pequeña nobleza (Ferrer Alos, 1991, 2005a, 2008). Las plazas que ofrecía la Iglesia para su funcionamiento (curatos, canongías, etc.) tenían un valor en renta que recibía quien ocupaba el cargo 7 . Las parroquias tenían un valor y los sacerdotes intentaban acceder a ellas por la renta que daban. Todo este entramado, sin embargo, tenía una capacidad limitada de absorción frente a la demanda de las familias, por lo que otra vía paralela y complementaria a la anterior fue la creación de beneficiados que generaban renta por sí solos o daban derecho al reparto de algunos ingresos generados por la Iglesia.

El acceso a estos cargos eclesiásticos se realizaba por distintas vías y, por tanto, era importante conocerlas para poder obtener las plazas deseadas. Los cargos eclesiásticos tenían detrás un derecho de presentación que había modelado el proceso histórico. Un monasterio o un señor feudal podía tener derecho de presentación del párroco de una parroquia, aunque con el paso del tiempo este derecho pasó a los obispos y en el concordato de 1753, al Rey. Se trataba pues de influir y relacionarse con quien tuviese este derecho de presentación y mover los hilos oportunos para acceder a la plaza correspondiente.

Lo importante pues era entrar en este mercado de plazas y de rentas. La vía que se utilizó fue la creación de personados, dotados con un capital, en un altar concreto, no perpetuo y extinguible a la primera o segunda generación. En Barcelona se crearon 361 entre 1687 y 1706, dotados con un capital de 210.405 libras (Fatjo Gomez, 1999, pp. 180-221), y en Girona se crearon 2219, entre 1600 y 1699, con un capital de 745.495 libras, y luego 1708 entre 1700 y 1786, con un capital de 1.753 .505 libras (Marques, 1999, p. 156). La familia creaba el personado y el eclesiástico obtentor ya estaba dentro. El capital era el valor en el punto de salida. A partir de aquí empezaba un proceso de permuta con plazas de clérigos que querían ascender. El personado más una cantidad permitía acceder a una plaza de más renta que se podía acumular; la plaza más la renta posibilitaba acceder a otra plaza de más renta y así sucesivamente hasta que el cura salía del circuito eclesiástico permutando su última plaza. Salvador Ferrusola entró en el año 1699 con un personado de 700 libras, pasó por cuatro cargos eclesiásticos y salió al final del curato de Arenys de Mar con un capital de 6050 libras (Marques, 1999, p. 157). A menudo este capital retornaba a las familias de origen, de forma directa o por la vía de la fundación de causas pías o de beneficios eclesiásticos a favor de los descendientes de la familia.

Pero los eclesiásticos también intentaban pasar los cargos a sus familiares o favorecer permutas en este sentido. Mateo Llobet ya estaba en la catedral y se desprendió del beneficio de Sant Sebastiá que pasó a su sobrino Jaume Llobet, tonsurado en el año 1790 (Llobet Masachs, 2012, vol. II, p. 95). Otras veces era la vía de ser coadjutor de un canónigo la que preparaba el camino para este cargo y se escogía para ello a un familiar (Fatjo Gomez, 1999, pp. 41-51). Anton Vila, que era cura párroco de Artés, pasó el curato a su sobrino por la vía de la permuta (el sobrino permutó el curato de Talamanca por el nuevo que obtenía mejor dotado) (Ferrer Alós, 1991).

Aunque el Obispo tenía que dar su beneplácito, la mayoría de las plazas llegaban arregladas. Esta circulación de plazas era autónoma, y era la misma red de contactos entre eclesiásticos (en los entierros, las misas, etc.) la que permitía conocer este mercado. Pere Fatjó hace notar que el 38 \% de los curas de la catedral de Barcelona en el siglo XVII había tenído algún pariente o señala la existencia de linajes familiares entre los canónigos (los Amigant, los Dalmau, los Peguera, etc.) (Fatjo Gomez, 1999, pp. 94-95).

Algunas vacantes de provisión real necesitaban otros mecanimos de promoción. La familia LLobet de Vidreres había alojado a la Duquesa de Orleans en 1797 e intentaban utilizarla para acceder a cargos eclesiásticos: 
He sabido que el mayordomo de la Duquesa es abogado de primera clase, de manera que los abogados de Figueres y la Bisbal le han consultado negocios de mucha entidad y si te parece, escríbele, para que te informe de qué modo nos hemos de manejar por nuestras pretensiones y no lo dilatéis mucho. Infórmate primero con cautela de qué plazas están vacantes, sin hacer mención del Archidiaconato para no levantar sospechas, que si esto hubiese ido tan rápido ya lo hubiera hecho yo.

Por Navidad escribían al mayordomo de la duquesa y ya eran muy claros: "espero de su buena ley que me dirá si para las pretensiones de mi hermano y en caso de que no, sírvase insistirle que está vacante el Archidiaconato Mayor de la catedral de Girona" (Llobet Masachs, 2012, vol. II, p. 23).

La otra gran vía de acceso era la fundación de beneficios eclesiásticos. En este caso, una familia decidía invertir un capital en la creación de una plaza siempre con algunas obligaciones piadosas y ligada a una devoción religiosa concreta. La familia tenía el derecho de presentar quién tenía que ocupar la plaza. Las rentas provenían de los rendimientos del capital, pero también del derecho que se acababa teniendo -ello dependía del proceso histórico de cada plaza - a las rentas que generaba la práctica religiosa en la comunidad (pago de misas, asistencia a entierros y otras ceremonias religiosas, etc.). Algunos de estos beneficios estaban muy vivos y servían claramente para colocar a los hijos segundones de las familias y evitar o reducir así el descenso social (véase el caso del mas Vila del Soler en Artés) (Ferrer Alós, 1991); otros eran plazas muy antiguas, de poco valor en cuanto a capital pero que daban acceso a los derechos comunitarios de la Iglesia en que estaban fundados. Incluso los patronos habían ido evolucionando y cambiando a lo largo del tiempo. Para poner un ejemplo, el 12,2\% de los beneficios y capellanías de la catedral de Barcelona habían sido fundados en el siglo XIII, el 47,8 \% en el siglo XIV, el 23,3 \% en el siglo XV, el 12,2 \% en el siglo XVI y el 4,5 \% en el siglo XVII (Fatjo Gomez, 1999, p. 122). Esta antigüedad era la que hacía que el 34,2 \% de los patronos fueran nobles y ciudadanos honrados, el 24,6\% cabildos y canongías, el 18,9\% labradores, el 4,8\% oficios de la catedral, etc. (Fatjo Gomez, 1999, p. 130). En estos casos, el acceso a estas plazas no pasaba directamente por la familia, sino por los contactos dentro de la propia Iglesia o con los patronos, a menudo muy alejados de la institución.

Los beneficios familiares solían estar reservados a los hijos segundones que entraban a la Iglesia, normalmente uno por generación. Podríamos decir que cuando un ocupante moría pasaba a ser nombrado automáticamente su sobrino. Pero la biología no siempre funcionaba de forma matemática. Un obtentor podía vivir muchos años y dejaba sin plaza al futuro sobrino, o por el contrario podía morir joven y tener una plaza vacante. Entonces, era frecuente prestar los beneficios entre casas emparentadas gracias a la red tejida por las mujeres (Llobet Masachs, 2012). En el mas Vila del Soler de Artés tenemos algunos ejemplos: Joan Vancell era un beneficiado que no tenía aparentemente nada que ver con la familia, pero una hija del mas Vila había entrado de nuera en el mas Riera de Merola y una hija de este mas había entrado en el mas Vancell de Sant Esteve de Sisquer. Un segundón de este mas ocupaba el beneficiado del mas Vila del Soler que estaba vacante. Más adelante fue el mas Vila quien tenía el beneficio ocupado y fue el mas Oller (una de cuyas hijas había entrado en el mas Vila hacía un par de generaciones) quien prestó el beneficio (Ferrer Alós, 1991, pp. 54-55).

Los segundones de muchas familias se movían en este entramado de plazas utilizando la propia familia pero también la lógica autónoma de la institución que tenía sus propios mecanismos de reproducción social, que fueron cambiando progresivamente a lo largo del siglo XVIII, y sobre todo del siglo XIX, cuando todo este entramado prácticamente se derrumbó y la Iglesia dejó de tener interés para la colocación de los hijos.

\section{LA FAMILIA Y LA RED DE ECLESIÁSTICOS}

Además de como se accedía a los cargos y el papel que jugaba la familia, es obvio que los eclesiásticos jugaban también a favor de la red familiar. Por un lado, tenían acceso a una información privilegiada, en tanto integraban la principal institución de crédito por la que pasaba, además, la información sobre el estado de patrimonios en dificultades (Ferrer Alós, 1986). Asimismo, el hecho de residir en pueblos y ciudades les permitía conocer el mercado matrimonial y tener información sobre las familias con las que se querían 
establecer alianzas, o sobre los mercados de trabajo locales y los artesanos fiables con los que mandar hijos a aprender un oficio. Además, podían brindar alojamiento a los sobrinos que iban a estudiar para cura en la siguiente generación o iban a colocarse en algún oficio, y también tener referencias de criadas o mossos que estaban interesados en entrar en el mas para complementar sus ingresos.

\section{EMigraR a LA CIUDAD. LA RED URBANA DE LOS SEgUNDONES}

La entrada en la Iglesia no era posible para todas las familias ni para todos los hijos, por lo que otro destino de los segundones era buscar una colocación fuera de la casa, en un entorno próximo o emigrando a los centros urbanos donde se podía aprender un oficio. La legítima pagada al hijo se invertía en aprender una capacidad que a la larga podía proporcionar más recursos para invertir en tierras. Los parientes de la ciudad eran la vía para incorporar segundones de otras generaciones.

En el año 1785, el heredero del mas Galobart colocaba a su hijo Antón de aprendiz de cordonero en casa de Josep Babra, maestro de Manresa. Ocho años después colocaba a otro hijo -Pere- de aprendiz en casa del hermano que ya había hecho antes el aprendizaje y ya era maestro. Uno ayudaba a otro no solo acongiéndole de aprendiz, sino proporcionando la información necesaria conseguida en la red construida en el entorno urbano para que otro pariente pudiera entrar en ella.

La reconstrucción de la historia del mas Serra de Calders es una excelente muestra del funcionamiento de la red de hermanos. La correspondencia que se conserva muestra dónde estaban, cómo se preocupaban entre ellos y cómo unos ayudaban a otros: un hermano cura en Castellolí coloca a su sobrino en la misma Iglesia. Este sobrino se preocupa por su hermano e intercede frente al heredero para que le dé una viña y así se mantenga cerca de la casa para que le ayude.

Llogari Serra fue un segundón que, a mediados del siglo XVIII, fue a Manresa para aprender el oficio de tejedor de velos, con mucha suerte, ya que pasó a formar parte de una de las compañías sederas más importantes de la ciudad, que exportaba miles de pañuelos de seda a América (Serra Coma, s.d.) (Vila Despujol, 1988). La relación con el mas no se rompió en ningún momento. Así, Llogari Serra Vilarmau, segundón de la siguiente generación, fue a Manresa para aprender el oficio en casa de su tío y, en el año 1802, se embarcaba a Veracruz para dedicarse a sus negocios y como intermediario de la compañía en la que participaba su tío (Sola, 1988). La red no acabó aquí. Valentí Serra, segundón de la tercera generación, se embarcó hacia América en 1820 y fue a casa de su tío Llogari en Veracruz. Volvió a Barcelona en 1822, y en el año 1831 volvió a la Habana donde residió un tiempo Joan, otro hermano suyo (Serra Coma, s.d.). Alguno murió soltero y repartió su fortuna entre los sobrinos. La red familiar funcionaba para la colocación de los segundones que aprovechaban la experiencia de alguna generación anterior.

A principios del siglo XIX, el heredero Serra casó con la pubilla del mas Parai en Santa Maria de Corcó cerca de Vic. Da la impresión de que las relaciones con esta ciudad son importantes. A dos segundones se los mandó allí a estudiar. Se hospedaban en casa de viudas que obtenían así ingresos complementarios. El primer segundón acabó en Barcelona trabajando de aprendiz de droguero pero acabó haciéndose cargo de la masía paterna, ya que su hermano heredero vivía en el mas Parai con la pubilla. Valentí se fue a América pero acabó residiendo en Barcelona. Las cartas muestran el intercambio de información, de regalos, de productos del campo que van a Barcelona, etc. El parentesco funciona, la información circula y ello permite acomodar a los miembros de la familia. Joan entró de aprendiz en una tienda de Vic pero pronto fue a Barcelona a aprender también el oficio de droguero, y acabó comprando tierras en Sant Feliu de Llobregat. Manel se casó con una pubilla de Oristá con un patrimonio modesto. El pequeño acabó también trabajando en una tienda en Barcelona (Serra Coma, s.d.).

Así pues, el despliegue de los hijos segundones, fuese en la iglesia o fuese trabajando en algún oficio o en algún comercio, era una tupida red por la que circulaba la información familiar, la información económica que necesitaba ser conocida; a su vez, facilitaba el acceso a recursos de los nuevos segundones que se incorporaban 
a la red, y ello se hacía a través de la correspondencia y de los intercambios de productos apreciados por la casa y por aquellos que estaban lejos (embutidos, turrones, etc.). Si alguno moría soltero podía darse una redistribución de recursos que ayudaba a mantener el nivel social de todos ellos.

\section{LAS REDES INFORMALES O COMO ACCEDER A UNA MASOVERÍA}

El contrato de masovería permitía el acceso de una familia campesina a un mas y al cultivo de sus tierras, lo que implicaba la residencia en el mismo. El mas cultivado por un masovero era una masoveria. No era un contrato normal, ya que el mas estaba cultivado por el campesino que poseía el dominio útil pero se daban tres circunstancias en que se generaban masoverías:

a) una unificación patrimonial por la vía de un matrimonio heredero-pubilla que implicaba que una de las dos casas quedaba vacía;

b) por endeudamiento del campesino y compra por una institución eclesiástica, por un comerciante o burgués de la ciudad o por otro campesino que ya tenía una casa, entonces la casa vendida quedaba vacía;

c) en el siglo XIX, cuando los propietarios empezaron a dejar sus casas y se iban a vivir a la ciudad, solían construir una casa pequeña al lado de la principal que era ocupada por una familia de masoveros.

En algunas partes de Cataluña -Girona o Vic-, las masías eran más pequeñas y una familia poseía varias, por lo que cada una se cedía a una familia de masoveros, o el mas principal era fragmentado y en cada parte se construía una casa pequeña en la que residía un masovero que cultivaba las tierras. En los primeros casos, las masoverías no eran muy abundantes aunque se iban incrementando con el paso del tiempo, mientras que en el segundo caso, la masovería era una de las formas principales de acceder a la tierra ${ }^{8}$. El resultado final es que, detrás de la misma figura contractual, había masoverías muy distintas que proporcionaban rendimientos muy distintos. A unas podían acceder campesinos con pocos recursos (los mejor situados de los pequeños campesinos), y a otras, campesinos más acomodados (normalmente segundones de otras masías que tenían más capital y más conocimientos para gestionar una casa) (Congost, To, 1999; Maspons Anglasell, 1962).

\section{Figura 4}

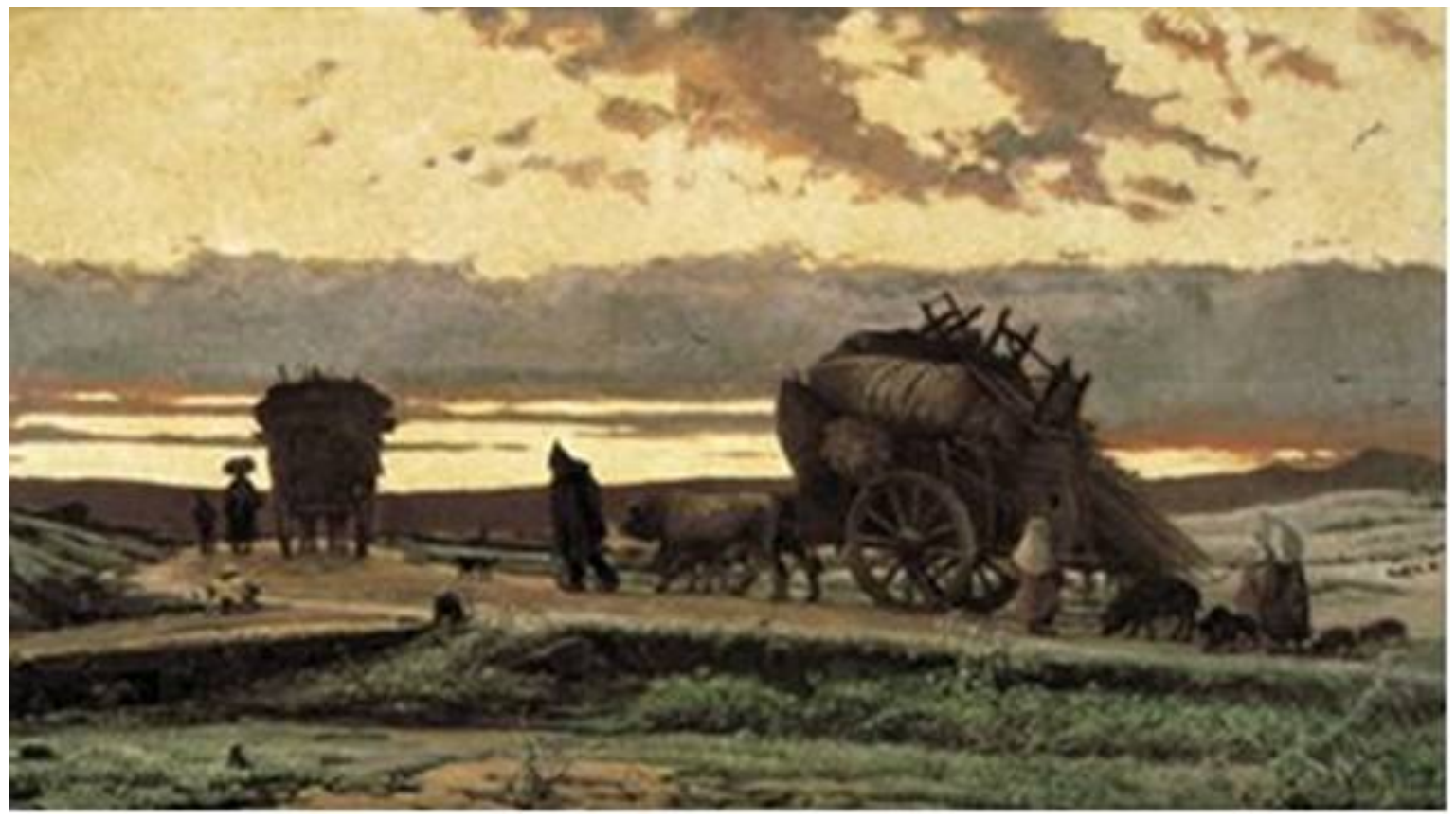

Reproducción de Recança de Joaquim Vayreda (1860) sobre el éxodo de los masoveros Fuente: Original en el Museu Nacional d'Art de Catalunya 
El contrato de masovería era a corto plazo (tres años obligarios y dos de voluntarios), aunque se renovaba de forma automática si ninguna de las partes lo denunciaba. A pesar del corto plazo, el contrato podía generar estabilidad (una familia masovera podía estar durante varias generaciones en la misma explotación) o podía cambiar a menudo. Era por Navidad que se producía el final del contrato y cuando las familias cambiaban de casa. Por las dos partes contratantes había razones para quedarse o dejar la casa. Para el propietario, un buen masovero era garantía de paz social y para el masovero, de estabilidad. Pero al masovero podía quedarle pequeña la casa y decidir buscar otra para progresar, o al propietario no gustarle cómo trabajaba el masovero, o que se generase un conflicto y decidiese cancelarlo. En otros casos, la demografia podía jugar en contra, al quedar el masovero sin heredero o no tener hijos y verse obligado a dejar la casa por no poder trabajarla. No se puede establecer una regla universal, pero la masovería era otra oportunidad en el mundo de los pequeños campesinos que aspirasen a mejorar su nivel social o de los segundones de masía que buscaban una salida al descenso social al que estaban condenados. Que una casa llevada a masoveria quedase vacía cuando se iba el masovero era una noticia que se propagaba en círculos informales, mercados y ferias para buscar nuevos o viejos candidatos a ocupar aquel espacio. Era una oportunidad en el mercado de trabajo.

La red de masoverías, aunque limitada, generaba un campesino que se definía como masovero y, una vez que conseguía este contrato, intentaba mantenerse en este estatus y normalmente construía una red familiar de acceso a masoverías que pasaban de padres a hijos. Pongamos un ejemplo, la familia Oliveras de Manresa en el siglo XVIII; no eran campesinos pobres ya que tenían algunas parcelas de secano y regadío en la ciudad y, sin embargo, los hijos acabaron controlando como masoveros las principales masías de la ciudad, las que fueron pasando de padres a hijos. Otro caso interesante es el de Jaume Torroella, que había salido del mas Torroella de la Vallsdelshorts, un mas que se había arruinado y vendido a finales del siglo XVII (Ferrer Alós y Plans Maestra, 2010, pp. 123-126). No sabemos si ya era masovero -tenía todos los conocimientos y capacidades-, pero sí que su hijo lo era del mas de la Coma de Sallent en el año 1725 cuando se casó con una hija de otro masovero. Sabemos que la familia ocupó la masoveria por lo menos hasta el primer tercio del siglo XIX ${ }^{9}$. El mas Torroella, que había sido vendido por deudas a finales del siglo XVII, fue dado en masoveria a la familia Galobart, pequeños campesinos de Artés y Avinyó a principios del siglo XVIII, segundones seguramente del mas Galobart de Calders. Isidro Galobart en el año 1693 era masovero del mas Magrans de Sallent. Joan Galobart, hijo de otro Galobart que había salido del mas de este nombre, se instaló de masovero en el mas Torroella de la Valldelshorts hacia el año 1700 y seguramente sus padres lo eran de algún mas de Avinyó ${ }^{10}$. Vivieron en el mas durante un siglo y acabaron comprando tierras para construir su propio mas (el mas Torroella de Baix) (Ferrer Alós y Plans Maestra, 2010).

En el mas Casals, próximo al anterior, hubo masoveros desde el siglo XVI. Sabemos los nombres de algunos de ellos que eran segundones de masías de los alrededores (Benet Graner del mas Graner de Navarcles, Jaume Torra del mas Torra del Pont, Salvador Tàpias del mas Tàpies, Jaume Xicola del mas Xicola de Corner, etc.). No son informaciones sistemáticas pero todo parece indicar que los segundones de masías eran buenos candidatos para ocupar masoverías.

Otros masoveros acabaron endeudados con el propietario, como Joan Planes, que lo era del mas Viladoms de Castellbell y el Vilar, y que debía al propietario 679 libras ${ }^{11}$. Otros cambiaban de casa muy a menudo, como una de las ramas de la familia Culubert en Girona que cambió varias veces a lo largo de su genealogía (Bosch Portell, 2010), o en Girona, donde de los 2133 contratos solo 213 eran una renovación; en el año 1764, de 529 masías solo en 52 se encontraba la misma familia de masoveros (Congost, 1990, pp. 176-178). 
Figura 5

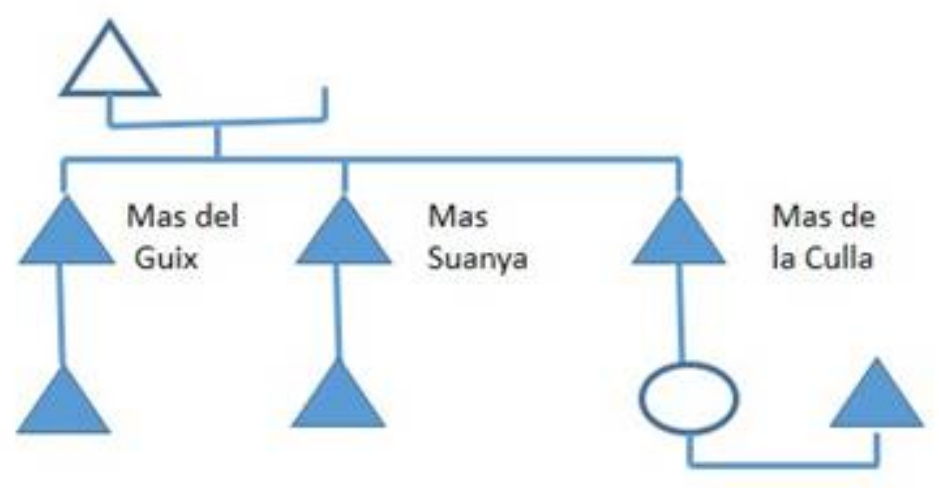

Masoveros de la familia Oliveras de Manresa en el siglo XVIII

Fuente: Elaboración propia a partir de la reconstrucción genealógica de esta familia

Aunque no se pueda cuantificar en detalle, deducimos que por un lado, algunas masoverias estaban bloqueadas por familias que estaban en ellas largo tiempo, y por otro, parece que en la mayoría eran frecuentes los cambios, por lo que había familias que se movían de unas a otras, otras que salían del sistema y otras que esperaban para entrar. Pequeños campesinos y segundones de masías pobres se movían en estas oportunidades.

Si el contrato era a corto plazo, podían producirse cambios ya fuese porque el propietario quería cambios o porque el masovero quería moverse porque consideraba que podía acceder a otra finca que le resultara interesante. Las vías de reclutamiento solían ser informales, a través de contactos en las ferias y mercados, a la salida de la iglesia, etc. Si alguien necesitaba alguno, se hablaba del tema con los círculos de trabajo próximos y de ellos surgía a menudo el conocimiento de alguien que podía estar interesado. A veces era el propio masovero que se marchaba el que podía aportar información sobre otros interesados -algún pariente o conocido- que se presentaban como propuesta al propietario. Curas, propietarios, tratantes y comerciantes eran una buena red de información sobre la situación del mercado laboral (Saguer Hom, 2005, p. 199).

\section{LAS REDES DE LOS PEQUEÑOS CAMPESINOS PARA COMPLEMENTAR LA LEGTÍTIMA Y LA DOTE}

Las familias acomodadas acumulaban recursos suficientes para poder financiar las dotes que servían para colocar a las hijas, o las legítimas para acceder a personados e iniciar una carrera en la Iglesia. Asimismo, tenían contactos suficientes para situar a algunos hijos en el artesanado urbano.

Los pequeños campesinos - con casa, huerto y alguna parcela a parcería- no tenían un patrimonio suficiente que generara los recursos para garantizar la subsistencia de la familia y mucho menos colocar a los hijos en el mismo nivel social. Así pues, los recursos que faltaban tenían que buscarse fuera de la propia explotación familiar. El acceso al mercado de trabajo temporal era fundamental para estas explotaciones campesinas.

Deberíamos distinguir entre el acceso temporal que hacían los padres a los recursos externos y el camino que seguían los segundones de ambos sexos, que estaban condenados a buscar trabajo en el exterior con el objetivo de ahorrar los caudales suficientes para acceder al matrimonio y conseguir los recursos (casa y tierras) para convertirse en pequeños campesinos como sus padres, y recomenzar así el ciclo vital.

Los recursos externos podían ser diversos y los pequeños campesinos se adaptaban a ellos con total facilidad: recursos temporales como los momentos punta de las cosechas, jornales para trabajos concretos, actividades puntuales de transformación de recursos naturales, actividades protoindustriales, etc. Cada una 
de estas actividades generaba sus demandas específicas de trabajo y mecanismos concretos de acceso a ellas mediante redes o prácticas específicas. Intentemos esquematizarlos.

\section{LAS COLLES O CUADRILLAS}

Había muchos trabajos intensivos en mano de obra que se hacían mediante cuadrillas, de las que conocemos muy poco su funcionamiento (segar, vendimiar, recoger piñones, avellanas, etc.). ¿Cómo funcionaba el mercado de trabajo y se ponía en contacto la oferta y la demanda? En origen, una persona conocida como el capità era el que reclutaba a los miembros de la colla, entre conocidos y parientes. El capità cerraba los tratos con las casas en las que iban a trabajar de un año para otro; este itinerario se modificaba a partir de la información oral que circulaba entre las mismas. Si faltaban casas procuraba visitar por adelantado aquéllas en las que la colla podría trabajar. Pero este sistema no siempre resolvía el problema, de tal manera que había concentraciones de colles en el momento de empezar los trabajos, como si fueran grandes mercados de contratación. Uno de estos mercados era Calaf, donde las colles podían ser contratadas y donde intercambiaban información entre ellas (Amades, 1982 vol. III, pp. 700-701). Si las partes quedaban contentas con el trabajo, el capità cerraba el trato para el año siguiente y de esta manera el trabajo quedaba asegurado y se resolvía la incertidumbre (Amades, 1982, vol. III, p. 766).

\section{MOSSOS Y CRIADAS EN LAS MASÍAS}

Las colles eran la opción preferida para trabajos intensivos (cosechas), mientras que había trabajos que demandaban mano de obra más estable, lo que no quería decir que fuera muy especializada. De la misma manera, los hijos e hijas segundos de pequeños campesinos necesitaban trabajar para poder ahorrar para la dote en el momento de casarse.

Algunos estudios dan pistas sobre estas opciones. En las masías, el 70/80 \% de los trabajadores eran varones, el 90/85 \% eran solteros y tenían entre 15 y 25 años, por lo que estaban poco tiempo en la casa o iban ascendiendo en los trabajos. La edad determinaba la ocupación. Los niños y niñas de 10 a 14 años trabajaban guardando piaras de cerdos (porcaters/ porcateres), ayudaban al pastoreo (rabadans), o cuidaban los bueyes (bovers). Las niñas podían ser también criades xiques. Cuando cumplían los 15 años podían convertirse en mossos agrícolas y podían ser contratados por meses o por años prorrogables. Continuaban cambiando de casa con facilidad y combinaban este trabajo con faenas en su casa de origen. A pesar de esta movilidad continuada, podía aparecer también el mosso que se iba quedando en la casa, soltero, y acababa conviritiéndose en una persona de confianza.

Las niñas se convertían en criadas y se dedicaban a trabajos domésticos: llevar la comida a los mossos, lavar la ropa, ir al molino, etc. El 73 \% estaba también menos de un año y la movilidad era muy grande.

El hecho de residir en la propia masía (otra opción no era posible por la lejanía entre lugar de trabajo y residencia) implicaba que el sueldo incorporaba la manutención y algunas prendas que se desgastaban con el trabajo (alpargatas), y una soldada o cantidad en dinero, que podía variar según el trabajo y según si se trabajaba en verano o en invierno (Roca Fabregat, 2005). En el mas Santmartí de Serraïma, a mediados del siglo XIX, trabajaban doce personas de forma permanente (cuatro mossos, un sagal, un bover, un porcater $o$ porcatera, un pastor, un rabadán, un arriero, dos criadas y algunas veces una nodriza (Sanmarti Roset, 1994, p. 155).

Debemos destacar que estamos frente a unos trabajadores muy jóvenes y solteros. Estos trabajos les servían a estos jóvenes para captar recursos que luego podrían aportar al matrimonio cuando se establecieran en sus pueblos de origen. ¿Cómo se contrataban estos trabajadores estacionales? Los datos de procedencia muestran que la mayoría eran de los pueblos immediatos, lo que indica que funcionaban las redes de proximidad 
(parientes de rabassaires, de otras personas que habían trabajado en el mas en el pasado, contactos en los espacios informales de los servicios, del mercado, etc.). La reproducción social del sistema familiar por parte de los pequeños campesinos dependía en parte de los recursos transferidos por los grupos sociales más acomodados.

\section{EL TRABAJO DE LAS MUJERES JÓVENES: LAS CRIADAS}

Las masías proporcionaban mayoritariamente el trabajo a los varones jóvenes, como hemos visto, y solo a una pequeña parte de las mujeres. ¿Dónde conseguían los recursos complementarios para el futuro matrimonio? El mundo urbano proporcionaba una gran cantidad de trabajo doméstico, especialmente a las mujeres. Así pues, muchas chicas jóvenes iban a la ciudad y, seguramente, regresaban para casarse. Conocemos muy poco este periplo, pero los datos son cada vez más concluyentes.

El estudio de los padrones municipales nos da pistas en este sentido. Los primeros son del primer tercio del siglo XIX. Las tasas de masculinidad en edades jóvenes son un buen indicador de esta presencia de mujeres en las ciudades.

Tabla 1

\begin{tabular}{|c|c|c|c|c|}
\hline & año & $16-20$ años & 21-25 años & 26-30 años \\
\hline Manresa & 1802 & 73,88 & 69,12 & 72,01 \\
\hline Reus & 1820 & 55,97 & 68,99 & 67,96 \\
\hline $\begin{array}{l}\text { Sant Feliu } \\
\text { de Guixols }\end{array}$ & 1824 & 83,06 & 84,54 & 84,54 \\
\hline Barcelona & 1863 & 84,46 & 87,92 & 87,42 \\
\hline
\end{tabular}

Tasas de masculinidad en algunos padrones de habitantes de ciudades catalanas en el año 1820 Fuente: Andreu, 1986b; Mateo, 2000; Saez, 1968; Vila-Masana Portabella, 2012

En los cuatro municipios de los que tenemos datos el número de mujeres era superior al de los varones, lo que atribuimos, por los datos cualitativos que tenemos, a la llegada de mujeres jóvenes para desempeñar diferentes oficios urbanos, especialmente el de criadas. En Reus había, en 1820, 374 criadas de las que el $75 \%$ eran nacidas fuera de la ciudad (Andreu, 1986a, p. 33). En Barcelona, en 1848, "la Cerdanya y el Ripollés eran áreas de reclutamiento de criadas que llegaban a Barcelona desde los 12 y 13 años de edad" (Lopez Guallar, 2004, p. 82). En 1863 se observa el mismo desequilibrio, "en efecto el número de inmigrantes femeninos entre los 11 y 20 años es muy superior a los inmigrantes masculinos (...) Es un centro de atracción de servicio doméstico" (Saez, 1968, p. 51).

En 1848, el 27,9\% de las criadas tenían entre 12 y 19 años y el 48,8 \% entre 20 y 39 años (Borrell, 2015, p. 80). Las tasas de masculinidad de estas ciudades se equilibra a medida que pasan los años, lo que nos indica que algunas de aquellas mujeres deberían dejar la ciudad para regresar a sus lugares de origen y casarse. Ser criada era una fase del ciclo de vida, en la que se acumulaban los recursos para pagar la propia dote necesaria. Una tercera parte de las mujeres de masoveros entrevistadas en Girona habían pasado por el servicio doméstico (Saguer, 2011, pp. 327-329).

¿Servían estos ingresos para poder acceder al matrimonio? No es fácil documentarlo, pero algunos capítulos matrimoniales dejan entreverlo. En el año 1797, Joan Galobart Pla se casaba con una pubilla de Navarcles. La legítima aportada por su familia era de 10 libras pero aportó 150 libras de ahorros propios. En el año 1824, Sebastià Galobart Bosch se casó con Francisca Codina. Su legítima era de 30 libras, pero aportó 150 al matrimonio que había ahorrado de su trabajo como arriero ${ }^{12}$. 


\section{Conclusiones}

En una sociedad rural es la definición de la estructura de la propiedad (que es una de las vías de acceso a los recursos) y el sistema familiar (que coloca a cada individuo en un papel frente a la reproducción social) lo que nos ayuda después a definir el funcionamiento de las redes a través de las cuales los individuos resuelven su acceso a los distintos recursos. Sin este planteamiento las redes se convierten en abstractas y los conceptos no suelen tener sentido.

La tierra, en buena parte de Cataluña, estaba organizada en explotaciones agrarias denominadas masos; dentro de cada uno había una casa llamada masía en la que residía el campesino. Estamos hablando de explotaciones que podían superar las $80 / 100$ ha en buena parte del país. Necesitaban mano de obra estacional y estable para el cultivo directo de la tierra y podían ceder la tierra a terceros para ser cultivada. Estas familias utilizaban el sistema de heredero único con la idea de que para la reproducción social era mejor mantener la casa en manos de un hijo que cuidara de sus padres, colocara a sus hermanos y fuera refugio en caso de dificultad.

Entender la lógica del sistema hereditario es fundamental para comprender las posibilidades de los individuos. Implicaba, de entrada, que el heredero se casaba socialmente hacia arriba y los segundones hacia abajo. Que las mujeres solían casarse y entrar en casa de un heredero de nivel social inferior a la casa de la que salían. Y que era a través del matrimonio que se producía un encadenamiento social hacia abajo y hacia arriba que permitía que individuos de nivel social diferente estuvieran en contacto a través de la red de parentesco.

Asimismo, las mujeres eran las que permitían tejer las alianzas con otras casas y ello se traducía en los intercambios de todo tipo (económicos, de información, de beneficios eclesiásticos, de mano de obra, de opciones de matrimonio, etc.). Los hijos varones que quedaban solteros en casa entraban en la Iglesia o iban a la ciudad a aprender un oficio, se convertían también en otra red de acceso a otros recursos aprovechados por los miembros de nuevas generaciones. Hemos analizado como, en estas ubicaciones, los eclesiásticos o los artesanos ayudaban a generaciones de las mismas casas.

A todo ello habría que añadir el parentesco ficticio (padrinos y madrinas de bautismo) que religaba al hijo que nacía con tíos y tías de ambos lados de la familia, a veces instalados en el campo o en la ciudad a través de los oficios, o con individuos amigos de la familia. A pesar del carácter simbólico, se generaba una obligación hacia el ahijado que duraba toda la vida y que podía ser útil en determinadas circunstancias.

El complemento necesario de las masías eran los pequeños campesinos de las villas y pueblos. Su patrimonio era escaso o insuficiente para colocar a todos los hijos, por lo que la mayor parte de ellos tenían que dejar la casa de niños para procurarse recursos fuera de ella. Las masías eran la base de la demanda de mano de obra joven y temporal para cultivar las tierras o ayudar en la casa. Eran los mossos y criadas que, de forma temporal, trabajaban en las masías. Su objetivo era ahorrar para acumular una cantidad suficiente que les permitiera establecerse y casarse como pequeños campesinos en los mismos pueblos, cultivando tierras cedidas a aparcería por los propios campesinos acomodados.

La demanda de trabajo intensivo en las masías se concentraba especialmente en los momentos de la cosecha o en determinados trabajos (carboneo, elaboración de tejas y ladrillos, etc.), por lo que se organizaban colles que, de forma temporal, trabajaban en las casas y proporcionaban también recursos complementarios.

Asimismo, aquellas masías que quedaban vacías por venta de la explotación por endeudamiento o por unificación patrimonial se cultivaban a través del contrato de masovería que obligaba al campesino a residir en la masía y cultivar sus tierras. Esta era una situación mejor que la del pequeño campesino.

Estas realidades se derivaban de una estructura de la propiedad (y los diversos tipos de acceso a la tierra) y de un sistema familiar determinado, y definían las características de los nodos de las redes en las que se movían los individuos para acceder al mercado de trabajo y al mercado matrimonial. En este trabajo hemos intentado presentar estas redes y su funcionamiento. 


\section{REFERENCIAS}

Amades, J. (1980). Folklore de Catalunya. Costums i creences. Barcelona: Selecta.

Amades, J. (1982). Costumari català. Barcelona: Salvat Editors / Edicions 62.

Andreu, J. (1986a). Economia i societat a Reus durant la crisi de l'Antic Règim. Reus: Associació d'Estudis Reusencs.

Andreu, J. (1986b). Població i vida quotidiana a Reus durant la crisi de l'Antic Règim (1700-1850). Reus: Centre de Lectura de Reus.

Barrera, A. (1990). Casa, herencia y familia en la Cataluña rural. Madrid: Alianza Editorial.

Borrell, M. (2015). El servei domèstic a la ciutat de Barcelona (1900-1950). Barcelona: Universitat de Barcelona.

Bosch Portell, M. (2010). Movilidad y herencia de los masovers catalanes. La familia Culubret, siglos XVII-XIX. Historia Agraria, 52, 45-74.

Colome Ferrer, J. (2003). L'explotació de la terra: el contracte de rabassa morta. En D.D.A.A., De l'aiguardent al cava. El procés d'especialització vitivinícola a les comarques del Penedès-Garraf (pp. 225-238). Barcelona: Tres de vuit.

Congost Colome, R., Gifre Ribas, P., Saguer Hom, E., y Torres, X. (1999). L'evolució del contracte de masoveria (Girona, s. XV-XVIII). En R. CONGOST, L. E. TO (Eds.), Homes, masos, història. La Catalunya del Nord-est (segles XI-XX) (pp. 269-298). Barcelona: Publicacions de l'Abadia de Montserrat.

Congost, R. (1990). Els propietaris i els altres. Vic: EUMO.

Congost, R., Jover, G., y Biagioli, G. (2003). L'organització de l'espai rural a l'europa mediterrània. Masos, possessions, poderi. Girona: CCG Edicions.

Congost, R., y To, L. (Eds.) (1999). Homes, masos, història. La Catalunya del Nord-est (segles XI-XX). Barcelona: Publicacions de l'Abadia de Montserrat.

Fatjó Gómez, P. (1999). La catedral de Barcelona en el siglo XVII. Las estructuras y los hombres. Barcelona: Universitat de Barcelona.

Ferrer Alós, L. (1986). L'església com a institució de crèdit: les quotidianes distribucions de la Seu de Manresa. Recerques, 18, 7-46.

Ferrer Alós, L. (1987). Pagesos, rabassaires i industrials a la Catalunya Central (s. XVIII-XIX). Barcelona: Publicacions de l'Abadia de Montserrat.

Ferrer Alós, L. (1991). Familia, Iglesia y matrimonio en el campesinado acomodado catalán (s. XVIII-XIX). Boletín de la ADEH, IX(1), 27-64.

Ferrer Alós, L. (1993). Fratelli al celibato, sorelle al matrimonio. La parte dei cadetti nella riproduzzione sociale dei gruppi agiati in Catalogna (secoli XVIII-XIX). Quaderni Storici, XXVIII(83), 527-554.

Ferrer Alós, L. (1998). La vinya al Bages. Mil anys d'elaboració de vi. Manresa: Centre d'Estudis del Bages.

Ferrer Alós, L. (2004). Kinship as a mechanism in the social structuring of Rural Catalonia (eighteenth and nineteenth centuries). Journal of Family History, 29(2), 135-153.

Ferrer Alós, L. (2005a). Fills a l'església. Una estratègia de reproducció de la petita noblesa a la Catalunya Central (segles XVII-XVIII). En D.D.AA, Església, societat i poder a les terres catalanes de parla catalana (449-472). Valls: Cossetània Edicions.

Ferrer Alós, L. (2005b). When there was no male heir. The transfer or wealth in Catalonia trough women in Catalonia (the pubilla). Continuity and Change, 20(1), 27-52.

Ferrer Alós, L. (2007). Hereus, pubilles i cabalers. El sistema d'hereu a Catalunya. Catarroja: Afers.

Ferrer Alós, L. (2008). Placing sons and daughters in the church: Strategies used by the gentry of Central Catalonia to maintain social status in the 17 th and 18 th centuries. The History of the family. An International Quarterly, $13,26-41$.

Ferrer Alós, L. (2011). Apparition, évolution et logique des contrats de marriage en Catalogne (XVIème-XIXème siècles). Annales de Démographie Historique, 1, 23-48. 
Ferrer Alós, L. (2014). Derechos de propiedad y mercado de la tierra en la Catalunya Vella (s. XV-XIX). El caso de Artés (Bages) Historia Agraria, 62, 47-82.

Ferrer Alós, L. (2015). La formació d'una estructura de la propiedad de la terra a la Catalunya Vella (segles XVI-XIX). Manuscrits, 33, 67-93.

Ferrer Alós, L., Plans Maestra, J. (2010). De la Valldelshorts i Montpeità al poble de Torroella de Baix. Sant Fruitós de Bages: Ajuntament de Sant Fruitós de Bages.

Jimenez Sureda, M. (1997). L'església catalana sota la monarquia dels Borbons. La catedral de Girona en el segle XVIII. Barcelona: Universitat Autònoma de Barcelona.

Lopez Guallar, P. (2004). Naturales e inmigrantes en Barcelona a mediados del siglo XIX. Quaderns d'Història, 11, 69-86.

Llobet Masachs, S. (2012). Historia de una familia: los Llobet de Vidreres (siglos XII-XX). Vidreres: personal.

Marques, J. (1999). Els personats i permutes de beneficis al Bisbat de Girona (segles XVI-XVIII). Annals de l'Institut d'Estudis Gironins, XL, 145-183.

Maspons Anglasell, J. (1962). El contracte de masoveria. En D.D.A.A., Miscel.lània Borrell i Soler (249-260). Barcelona: Institut d'Estudis Catalans.

Mateo, J. (2000). Anàlisi d'alguns aspectes de la població guixolenca del 1824. L'Artau, 37. (6-12)

Munno, C. (2005). Prestige, integration, parentèle: les reseaux de parrainage dans une communauté de Venetie (1834-1854). Annales de Démographie Historique, 1(109), 95-130.

Planes Albets, R. (1983). El creixement econòmic del segle XVIII a la Catalunya Interior: aproximació al cas del Solsonès i la seva comarca (Tesis de llicenciatura), Universitat de Barcelona, Barcelona, España.

Roca Fabregat, P. (2005). ¿Quién trabajaba en las masías? Criados y criadas en la agricultura catalana (1670-1870). Historia Agraria, 35, 49-92.

Ros Massana, R. E. (2010). Els capítols matrimonials. Una font per la història social. Girona: CGC Edicions.

Saez, A. (1968). La población de Barcelona en 1863 y 1960. Madrid: Moneda y Crédito.

Saguer, E. C. (2011). Forçats a foc i llum. Una història oral dels últims masovers de la regió de Girona (1930-2000). Barcelona: Generalitat de Catalunya.

Saguer Hom, E. (2005). Els últims hereus. Història oral dels propietaris rurals gironins (1930-2000). Barcelona: Generalitat de Catalunya. Departament de Cultura.

Sanmarti Roset, C. (1994). El treball assalariat en els masos de la Catalunya interior al segle XIX: el mas Santmartí. Estudis d'Història Agrària, 10, 143-156.

Serra Coma, R. (s.d.). La família Serra (1329-1892). Calders: Ed. familiar.

Sola, A. (1988). Un indià del Bages: Llogari Serra i Vilarmau. Dovella, 29, 5-11.

Torras Elias, J. (1984). Especialización agrícola e industria rural en Cataluña en elsiglo XVIII. Revista de Historia Económica, II(3), 113-128.

Torres, X. (1995). La Vall de Torelló als segles XVI i XVII: una història de paraires i bandolers. Vic: Eumo.

Vila-Masana Portabella, J. (2012). El padró de Manresa de 1824 (I). Dovella, 110, 22-29.

Vila Despujol, R. (1988). Una família burgesa manresana en la Catalunya del segle XIX. Els germans Serra-Farreras (1797-1877). Manresa: Caixa d'Estalvis de Manresa.

Violant Simorra, R. (1992). El cicle individual i familiar al Pallars. Tremp: Garsineu.

\section{Glosario de Abreviaturas y Acrónimos}

Aplec: Fiesta popular que suele celebrarse en una capilla o ermita con participación de los vecinos de la comunidad y de otras circundantes.

Bover: Mozo o chico joven que cuida de los bueyes. 
Capità: Se refiere a la persona que dirige una “colla”, va por las casas donde trabajarán sus componentes, pacta los precios, organiza los trabajos...

Colles: Grupos de trabajadores organizados que van por las casas para realizar determinados trabajos (segar, vendimiar, esquilar ovejas, aserrar madera...).

Conco: Segundón soltero que vive en la masía con su hermano heredero.

Criades xiques: Chicas muy jóvenes que entraban de criada en una casa.

Jove: Referida a la mujer casada con el heredero. Significa joven porque es la mujer joven que entra en la casa, en contraposición con la mujer que entró en la generación anterior (vella o vieja).

Mas: Explotación agraria característica de Cataluña que implica la residencia de la familia campesina en una casa construida en su interior que se conoce con el nombre de masía. Su extensión puede variar pero se sitúa en torno de las $60 / 100$ ha.

Masover: Campesino que cultiva un mas a través del contrato de masoveria.

Masoveria: Cuando un mas quedaba vacío (por endeudamiento de los propietarios o por unificaciones patrimoniales), el mas se cultivaba a través del contrato de masoveria. Una familia campesina iba a vivir a la casa y pagaba una parte de la cosecha por el cultivo de las tierras.

Mona: Pastel típico que los padrinos regalan a sus ahijados el día de Pascua.

Mosso: Trabajador, normalmente joven, que trabaja en el mas durante un tiempo.

Paraire: Oficio relacionado con la preparación de la lana (limpieza y cardado de la misma). Suele ser el que organiza redes protoindustriales de tejidos de lana.

Porcater: Chico joven que cuida de los cerdos de la casa.

Pubill: Segundón que se casa con una pubilla y va a vivir a la casa de ésta.

Pubilla: Nombre que recibe la heredera cuando no hay heredero varón.

Rabadà: Chico joven que aprende el oficio de pastor.

Rabassa morta: Contrato para plantar viña en un periodo de tiempo que duraba mientras vivían las cepas. Se pagaba una parte de la cosecha.

Recança: Tristeza, melancolía frente a una situación determinada.

Rosers: Se refiere a las fiestas del rosario en las que se negociaban muchos matrimonios.

Sagal: Chico joven que trabajaba en el mas.

Unclu: Segundón soltero que vive en la masía. Equivale a tío, o hermano del heredero visto desde los hijos de este.

Vella: Referida a la mujer casada con el heredero más antiguo en contraposición a la jove (joven) que entra en la casa para casarse con el futuro heredero. 


\section{Notas}

1 Página web: sites.google.com/sites/llorencferreralos. HAR2017-84030-P, Mundos del trabajo en transición (1750-1930): cualificación, movilidad y desigualdades.

2 En el mas Serra de Calders hubo un matrimonio entre el heredero y una pubilla de El Esquirol, un pueblo a muchos kilómetros del primero. La información de que había una casa con pubilla la dieron los frailes mendicantes que pasaban por la casa de Calders (Serra Coma, s.d.)

3 Marc se casó con Petronila Roura, pubilla del matrimonio Roura de Maçanet de la Selva, Elisabeth con Rafael Geronès, ciudadano honrado de Barcelona y labrador de Bescanó, y otra hija, Estefanía, con Joan Bofill de Tordera. Todos estos patrimonios suministraban los cerdos que comercializaba en salazón la sociedad Ferro \& Llobet (Llobet Masachs, 2012, vol. I, pp. 62-63)

4 Véanse los datos sobre estas familias elaborados a partir del Archivo Parroquial de Horta (Arxiu Diocesà de Vic). Joan Pla se casó en segundas nupcias con Bonaventura Torrentó. Su hermana con Pere Roqueta con quien no tuvo hijos y se casó en segundas nupcias con el sobrino del heredero. Una hija, Mercedes Torrentó Pla, se casó con su primo segundo Joan Roqueta Pla.

5 R. Violant habla de la fireta de la Pobleta de Bellvehí, la feria de la Pobleta de Segur, la de Vilaller, la del Rosario de les Iglesias, etc. En todas las comarcas existían estos lugares de encuentro y socialización para poder contactar y generar los pactos que acabarían en enlaces matrimoniales y alianzas entre las familias.

6 "Lazo torcido en el delantal, busca marido"; "Delantal al revés no busca prometido", "Delantal en forma de caracol, quiere un prometido". Los refranes tienen rima en la lengua original.

7 En el año 1761, por ejemplo, las dignidades de la catedral de Girona tenían el siguiente valor: Ardiaconat Major, 1500 libras; Sagristia major, 403 libras; Cabiscolia major, 600 libras; Abadia de Sant Feliu, 745 libras; Ardiaconato de Besalú, 335 libras; Ardiaconato de l'Empordà, 645 libras; Ardiaconato de La Selva, 429 libras, y el Deganato, 868 libras (Jimenez Sureda, 1997, pp. 61-62)

8 La condición de masovero no era socialmente igual en todas partes aunque el contrato y la filosofía del acceso a la tierra fuese el mismo. En los alrededores de Barcelona, por ejemplo, el masovero era un campesino acomodado porque conseguía mucho valor añadido con la agricultura intensiva necesaria para producir los alimentos para alimentar Barcelona. En cambio, en el interior, el masovero no tenía esta condición. A finales del siglo XIX, algunos masoveros se enriquecieron o fueron capaces de comprar tierras porque se aprovechaban de la ausencia de los propietarios. Las reflexiones que hacemos son para el siglo XVIII y mediados del siglo XIX.

9 Not. Ferrusola Cap 1722-1736, 11-XI-1725, fol. 111, Not. Ferrusola 1759, p. 268, Not. Vilacendra 1818, 25-XI-1818, fol. 329, AHCM.

10 Not. Ferrusola 1749, p. 275, AHCM.

11 Not. Masramon 1786, 22-IV-1786, fol. 135, AHCM. Véanse también los ejemplos que aporta (Planes Albets 1983 vol. I, 278)

12 Base de datos sobre la familia Galobart elaborada por los descendientes de esta familia. 